
\title{
$\begin{array}{ll}\text { Research Square } & \text { Preprints are preliminary reports that have not undergone peer review. } \\ \text { They should not be considered conclusive, used to inform clinical practice, }\end{array}$ \\ Comparison of the therapeutic effect of BMSCs and culture supernatant injection therapy on osteoarthritis and mechanism exploration
}

\section{Yiqi Peng}

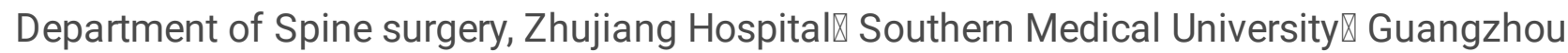

\section{Rui Zhao}

Department of Biochemistry and Molecular Biology,School of Basic Medical Sciences,Southern Medical University, Guangzhou

\section{Sheng Huang}

Department of Urology, Zhujiang Hospital,Southern Medical University,GuangZhou

\section{Shilin Xiong}

Deparment of Biochemistry and Molecualr Biology, School of Basic Medical Sciences, Southern Medical University, Guangzhou

\section{Qitao Yan}

Key Laboratory of Aged Infection and Organ Function Support, General Hospital of Southern Theatre Command, Guangzhou

\section{Anmin Jin}

Deparment of Spine surgery, Zhujiang Hospital, Southern medical University $\mathbb{G}$ Guangzhou zhenghong yu ( $\nabla$ yuzhenghongdyx@163.com)

Orthopaedic surgery, The people's Hospital of henan provincez, Zhenzhou, China https://orcid.org/0000-0001-9445-1133

\section{Research article}

Keywords: BMSCs, Osteoarthritis, osteoarthritic chondrocytes, Co-culture, OA model, IL-10/TNF-a ratio

Posted Date: May 15th, 2020

DOI: https://doi.org/10.21203/rs.3.rs-25515/v1

License: (c) (1) This work is licensed under a Creative Commons Attribution 4.0 International License. Read Full License 


\section{Abstract \\ Background}

Osteoarthritis (OA) is a chronic disease that can cause disability. The prevalence of osteoarthritis has increased year by year, become a disease that mainly causes the elderly to suffer. With the increasing understanding of bone marrow mesenchymal stem cell (BMSC) in tissue repair, BMSCs shown good therapeutic effects in OA, it may be due to BMSCs exerted their capacities of differentiation, secretion and immunoregulatory in the joints. As previous describe, BMSCs culture supernatant is proved that rich in multiple cytokines. Therefore, how BMSCs injection therapy exerts its ability to exert therapeutic effects, and whether its therapeutic effect can be replaced by its culture supernatant has become the focus of this article.

\section{Methods}

In vitro, we designed a co-culture system to deepen understand this new stem cell therapy. Through two kinds of cells cultured alone, direct and indirect cell contact co-culture to observe changes in cell morphology, quantity and cytoplasmic glycoprotein of these two types of cells and changes of the level of growth factor in the culture supernatant to explore the interaction of these two types of cells; in vivo, we induced an OA model and Injected Saline solution, BMSCs and their culture supernatants respectively for treatment, then we compared the improvement results of OA by evaluating changes in the cartilage layer after different treatments. And determine the changes of some growth factors and inflammatory factors in synovial fluid to analyze the possible mechanisms of multiple treatments.

\section{Result}

In the co-culture system, it was found that the direct co-culture of BMSCs and OCs can enhance the proliferation ability of OCs, OCs can retain more cytoplasmic glycoprotein, and BMSCs did not occurred abnormal differentiation during the co-culture. In animal experiments, it was found that the ability of BMSCs injection treatment has obvious therapeutic effect on $O A$, and the effect is better than its supernatant injection treatment. BMSCs therapy reduced matrix loss in articular cartilage cells, and reduced type I collagen production and fibrosis on articular cartilage, effectively regulating EGF and TGF$\beta 1$ change and inhibited intra-articular inflammation. Supernatant injection treatment will not significantly delay the progress of $\mathrm{OA}$, and it cannot replace BMSCs for the treatment of OA.

\section{Conclusion}

BMSCs therapy is a potential new therapy for OA. The secretion and regulation ability of BMSCs plays an important role in the treatment process. BMSCs are activated by the intra-articular environment of OA, 
regulating growth factors such as EGF and TGF $\beta$ to promote articular cartilage regeneration, and reducing intra-articular inflammation by regulating inflammatory factors and delaying the progression of OA. These effects cannot be replaced by the culture supernatant which is rich in multiple factors, and its regulation function requires the presence of BMSCs. These results provide a relatively comprehensive understanding of BMSCs cell therapy in OA and provide a new explanation for the possible antiinflammatory effects of BMSCs in the joint.

\section{Introduction}

Osteoarthritis (OA), is the most common cause of chronic pain and disability [1], is a degenerative disease characterized by cartilage degeneration caused by sports injuries, obesity, and increased age [2]. Meanwhile, $\mathrm{OA}$ is also a nonspecific chronic inflammatory disease affecting the entire joint, inflammatory was considered the condition a driver of the OA process [3,4]. As people's life expectancy is further prolonged, both its prevalence and incidence would be further increased [5]. OA directly leads to a decline in people's quality of life and creates a superior social and economic burden in all regions [6]. It will become a disease that can be overlooked.

There are currently no drugs that can cure OA. Clinically, drug treatment is mostly anti-inflammatory and analgesic, controlling symptoms, not suitable for long-term use, and cannot change the disease process [7]. Although surgical intervention can improve symptoms, it is only limited to the repair of focal defects [8]. Therefore, we still lack a treatment that is more comprehensive for $\mathrm{OA}$ and can alleviate further deterioration of the joints. MSC cell therapy, in particular BMSC, becomes a spotlight trend in new research recently. They had shown good therapeutic effects in many OA models, even reversing the ending of $O A[9-11]$.

BMSCs have excellent multi-directional differentiation potential and the ability to synthesize normal articular cartilage matrix [12], they also have capacities of growth factors secretion and immunoregulatory [13]. Several studies had also shown that intra-articular growth factor signaling and certain inflammatory factors were related to the occurrence and development of osteoarthritis [14-17]. The BMSCs culture supernatant was rich in multiple growth factors. However, BMSCs were a kind of cell that easily loses their abilities after multiple passages, they was difficult to expand in large quantities, and there was a study design showed that injection-treated MSCs do not survive long in vivo [18]. Therefore, it made sense to explore whether their culture supernatants replace them for treatment in OA. And it was unclear when exogenously injected BMSCs will exert their differentiation, secretion and immunoregulatory functions during cell survival in the treatment of OA. This cell therapy needs further exploration.

In vitro, the present study used a co-culture system to co-culture BMSCs with osteoarthritis chondrocytes, and the cell slices were evaluated by some kinds of staining kits and their supernatant was detected the relevant growth factors to explore the interaction between the two cells. In vivo, we used medial meniscus resection and anterior cruciate ligament transection (ACLT) surgery to induce moderate OA models in rats, 
followed to use the culture supernatant of BMSCs and BMSCs to treat moderate OA models respectively. We did not add any substances or scaffold. This was promoted to distinguish the understanding of how BMSCs or their secreted factors are involved in cartilage regeneration. And observed histological changes at 4, 6, 8 weeks after treatment. Meanwhile, the changes of growth factors TGF- $\beta 1$ and EGF in the synovial system and synovial fluid were examined to explore the role of these growth factors in the treatment of OA. To confirm the immunomodulatory capacity of BMSCs injection therapy in OA joints, the present study focuses on the factor IL-10 and TNF-a, they are important anti-inflammatory factor (IL-10) and pro-inflammatory factor (TNF-a) $[19,20]$. The present study examined the effects of different treatments on the concentrations of inflammatory factors IL-10 and TNF-a in joint synovial fluid, and evaluated the direction of inflammation by calculating the change in the ratio of IL-10 / TNF-a.Through analysis to evaluate the effect of different treatment methods on OA treatment.

\section{Materials And Methods}

\subsection{Animals}

Fifty-two healthy male specific pathogen free (SPF) Sprague-Dawley (SD) rats (aged 12 weeks, weighing between 225 and $250 \mathrm{~g}$ ) and four SPF SD neonatal rats (aged 10 days, weighing between 18 and $22 \mathrm{~g}$ ) were recruited for the study. All animals were provided by Laboratory Animal Center of Southern Medical University (Guangzhou, China). All experiments were approved by the Southern Medical University Experimental Animal Ethics Committee. Fifty-two SPF SD rats were acclimatized for 7 days before the experiments were initiated, 4 neonatal rats were used directly for BMSCs isolation.

\subsection{Surgical rat model of osteoarthritis and experimental grouping.}

Rats were divided in five groups: Normal $(n=12)$, Control $(n=12)$, Supernatant-injected $(n=12)$, BMSCinjected $(n=12)$, Model $(n=4)$. All groups except the Normal were induced Knee joint OA by medial meniscus extraction and ACLT surgery. As previously described [21], rats were carried out by abdominal anesthesia $(40 \mathrm{mg} / \mathrm{kg}$ ) with pentobarbital sodium at a concentration of $15 \mathrm{mg} / \mathrm{ml}$. Right knee joint was shaved and disinfected, a longitudinal incision was made on the right knee joint, joint cavity was exposed carefully, push away the patella extremely, the anterior cruciate ligament was transected and the medial meniscus was carefully removed. The drawer test used to check the surgical result. And then the patella was reset and the incisions were sutured layer by layer. After the operation, all rats were intramuscular injected penicillin (400,000 units) once daily and continued for 3 days. The rats were allowed to develop OA for 4 weeks without limitation of movement. Group Model was only used to isolate osteoarthritic chondrocytes after 4 weeks. Group Normal did not perform any surgery and was killed as planned with other groups.

\subsection{Isolation and culture of Rat bone marrow-derived mesenchymal stem cells (BMSCs)}


BMSCs were isolation and collect from the femora of four SD neonatal rats. Briefly, after euthanasia, femora were aseptically removed and immersed in phosphate-buffered saline (PBS) containing 100 $\mathrm{U} / \mathrm{mL}$ penicillin and $100 \mu \mathrm{g} / \mathrm{mL}$ streptomycin. Both ends of the femora were cut. Medullary cavity was exposed and the bone marrow was flushed using $5 \mathrm{ml}$ of PBS. The collected flushed suspension passed through $70 \mu \mathrm{m}$ Cell Strainer to remove the bone residue. After Centrifugation and removing PBS. The bone marrow cell was obtained from the cavities of these bones, followed by cell culture in Dulbecco's Modified Eagle Medium: Nutrient Mixture F-12 (DMEM/F-12, Gibco) containing 10\% fetal bovine serum (FBS), $100 \mathrm{U} / \mathrm{mL}$ penicillin and $100 \mu \mathrm{g} / \mathrm{mL}$ streptomycin. And then plated in T25 $\mathrm{cm} 2$ tissue culture flasks and cultured at $37^{\circ} \mathrm{C}$ in a humidified atmosphere of $95 \%$ air and $5 \% \mathrm{CO} 2$. Medium was replaced after one day in order to remove the non-adherent cell population. Subsequent medium exchanges were performed every 2 days until Cells were $80 \% \sim 90 \%$ confluence. The cells were treated with $0.25 \%$ trypsin $/ 0.02 \mathrm{mM}$ EDTA solution for passaging, seeded at a density of $1 \times 10^{\wedge} 5 \mathrm{cells} / \mathrm{cm} 2$, and cultured under the same conditions for expansion (passage 1). A part of BMSCs were collected at passage 2 and cryopreservation. Another part was cultured until passage 3 , and the BMSCs (passage 3 ) and its culture supernatant were collected used for the following experiments [22].

\subsection{Differentiation and Identification of BMSCs}

Adipogenic differentiation: Osteogenic differentiation: Cells were seeded in a 12-well plate at density of 5000 cells/cm2 and cultured with complete DMEM/F12 medium (10\%FBS, $100 \mathrm{U} / \mathrm{mL}$ penicillin and $100 \mu \mathrm{g} / \mathrm{mL}$ streptomycin) up to confluence. Adipogenic differentiation of BMSCs was induced by incubation with low glucose DMEM (gibco) supplemented with $10 \% \mathrm{FBS}, 100 \mathrm{U} / \mathrm{mL}$ penicillin, $100 \mathrm{\mu g} / \mathrm{mL}$ streptomycin, $10 \mu \mathrm{g} / \mathrm{mL}$ insulin, $200 \mu \mathrm{M}$ indomethacin, $50 \mu \mathrm{g} / \mathrm{mL}$ 3-isobutyl-1-methylxanthine (SigmaAldrich, USA) and $10 \mu \mathrm{M}$ dexamethasone. Medium was changed every 3 days, after 21 days of induction, cells were fixed with $4 \%$ paraformaldehyde and stained with Oil red O (Sigma-Aldrich, USA).

Osteogenic differentiation: Cells were seeded in a 12-well plate at density of 5000 cells/cm2 and cultured with complete DMEM/F12 medium (10\%FBS, $100 \mathrm{U} / \mathrm{mL}$ penicillin and $100 \mu \mathrm{g} / \mathrm{mL}$ streptomycin) up to confluence. Osteoblastic differentiation of BMSC was induced by incubation with low glucose DMEM (gibco) supplemented with $10 \% \mathrm{FBS}, 100 \mathrm{U} / \mathrm{mL}$ penicillin, $100 \mu \mathrm{g} / \mathrm{mL}$ streptomycin, $10 \mathrm{mmol} / \mathrm{L} \beta$ glycerophosphate(Sigma), $0.1 \mu \mathrm{mol} / \mathrm{L}$ dexamethasone(Sigma), $50 \mathrm{mg} / \mathrm{L}$ ascorbic acid (Sigma). Medium were changed every 3 days, after 21 days of induction, cells were fixed with $4 \%$ paraformaldehyde, and stained with Alizarin red (Leagene, Beijing).

The morphology of the Cells (passage 3) were observed by the inverted phase microscope. Phenotype of expanded BMSCs were evaluated by the expression of CD29 (ebioscience, FICT), CD90(ebioscience,PE), and CD45(Bioss,Cy7) molecules: BMSCs (passage 3,1 106 cells) were collected, washed twice by staining buffer; The antibodies CD29, CD90 and CD 45 were added to the cell suspension and incubated at $4{ }^{\circ} \mathrm{C}$ for 30 minutes. After the incubation, the cells were washed and the cell samples were collected and analyzed using the Amnis ImageStreamX Mark II Flow Cytometer System (Merck Millipore) system. 


\subsection{Isolation and identification of osteoarthritic chondrocytes.}

Osteoarthritic chondrocytes were isolated from rats in Model, which were euthanasia 4 weeks after surgery, the cells isolation and culture methods were according to a previously described [23, 24]. Briefly, after euthanasia, cartilage slices were collected from the proximal tibia and distal femur of OA rats. The cartilage slices were sterilized by PBS (containing $100 \mathrm{U} / \mathrm{mL}$ penicillin and $100 \mu \mathrm{g} / \mathrm{mL}$ streptomycin) for three times and cut into pieces $(\mathbb{1} \mathrm{mm} 3)$ by surgical scissors. These pieces were digested primarily with $0.25 \%(\mathrm{w} / \mathrm{v})$ trypsin for $30 \mathrm{~min}$ at $37^{\circ} \mathrm{C}$ and the supernatants were discarded. Then the pieces were incubated with $0.2 \%$ type II collagenase for $4 \mathrm{~h}$ at $37^{\circ} \mathrm{C}$. Subsequently, the chondrocytes were resuspended and filtered through a 70- $\mu \mathrm{m}$ cell strainer to remove the residues and cultured at $1 \times 106$ cells $/ \mathrm{mL}$ in six-well plate at $5 \% \mathrm{CO} 2$ and $37^{\circ} \mathrm{C}$ in a tissue culture incubator. The complete DMEM/F12 medium was supplemented with $10 \% \mathrm{FBS}, 100 \mathrm{U} / \mathrm{mL}$ penicillin and $100 \mu \mathrm{g} / \mathrm{mL}$ streptomycin. Confluent chondrocytes were passaged using trypsin at a ratio of 1:2 and primary chondrocytes were used throughout the study. The morphology of the primary osteoarthritic chondrocytes were observed by the inverted phase microscope. Toluidine blue staining was used to identify chondrocytes

\subsection{Co-culture and study design}

The cryopreserved BMSCs (passage 2) were recovery and continue cultured to passage 3 . Before cell seeding, nine $8 \mathrm{~mm}$ diameter round cell slides were paved at the bottom of each well of six-well plates. Primary osteoarthritic chondrocytes and passage-3 BMSCs were used in the co-culture experiments at a ratio of 2:1 [25]. For this design, as described previously [26],four groups were set up (Table1): (1) OCs Alone: osteoarthritic chondrocytes were cultured alone; (2) BMSCs Alone: BMSCs were cultured alone; (3) Direct Co-culture: osteoarthritic chondrocytes and BMSCs were mixed and seeded in the six-well plate; (4) Indirect cell-cell contact: BMSCs were seeded onto transwell inserts (six-well plates, $0.4-\mu \mathrm{m}$ porous membrane, BD Biosciences) and lowered wells were seeded with OCs.

All cells were cultured in F-12 (DMEM/F12; Gibco) containing 5\% FBS (Gibco), $100 \mathrm{U} / \mathrm{mL}$ penicillin and $100 \mathrm{U} / \mathrm{mL}$ streptomycin. Cell were inoculated in the number of previously described [27]. Cell culture supernatant of each group was collected on day $0,1,2,3,4,5,6,7$ and immediately frozen at $-80^{\circ} \mathrm{C}$ until analysis. The cell slides were harvested on day 3 and day 7 . 
Table 1

Cell seeding number and grouping.

\begin{tabular}{|lllll|}
\hline group & Cell type & Six-well plate & Transwell & Total \\
\hline OCs Alone & Osteoarthritic chondrocytes & $3.0 \times 10^{\wedge} 4$ & & $3.0 \times 10^{\wedge} 4$ \\
\hline BMSCs & & \\
\hline BMSCs Alone & Osteoarthritic chondrocytes & & $3.0 \times 10^{\wedge} 4$ \\
\hline & BMSCs & $3.0 \times 10^{\wedge} 4$ & \\
\hline Direct Co-culture & Osteoarthritic chondrocytes & $2.0 \times 10^{\wedge} 4$ & & \\
\hline & BMSCs & $1.0 \times 10^{\wedge} 4$ & & \\
\hline Indirect Co-culture & Osteoarthritic chondrocytes & $3.0 \times 10^{\wedge} 4$ & & \\
\hline & BMSCs & & $1.5 \times 10^{\wedge} 4$ & $4.5 \times 10^{\wedge} 4$ \\
\hline Note: OCs: osteoarthritic chondrocytes. & & & \\
\hline
\end{tabular}

\subsection{Histology of cell slides}

Cell slides were washed off Medium by PBS and fixed immediately in 4\% paraformaldehyde for 10 minutes when they were harvested on day 3 and day 7 in all group. The cells slides were evaluated by Toluidine blue staining, Trap staining and Alizarin red staining. Three views were randomly selected to evaluate the results of histological staining and count positive cells. Toluidine blue staining was scored according to the staining intensity in a similar way as previous study [19]. It rated the intensity of staining on a scale of 0 to $4: 4$, normal; 3 , slight reduction; 2 , moderate reduction; 1 , severe reduction; 0 , no staining.

\subsection{Treatment regimens of OA rats}

At 4 weeks after surgery, the right knee of rats in Control received intra-articular injection of $60 \mu \mathrm{l}$ PBS, Supernatant-injected received intra-articular injection of $60 \mu$ culture supernatant and BMSCs-injected received intra-articular injection of $1 \times 10^{\wedge} 6 \mathrm{BMSC}$ suspended in $60 \mu \mathrm{lPBS}$, Normal without intervention. Four rats of each group above were sacrificed at 4, 6, 8 weeks respectively after treatment. Synovial fluid in the joint cavity was flushed immediately with $1 \mathrm{ml}$ of saline, collected and frozen at $-80^{\circ} \mathrm{C}$ until analysis. The proximal tibia and distal femur of all rats were collected and fixed immediately in $4 \%$ paraformaldehyde for 1 day. The fixed samples were immersed in the decalcifying solution (10\% EDTA, Solarbio) for 4 weeks. After that, the bone samples were paraffin-embedded. Paraffin samples were selected the coronal plane direction to slice.

\subsection{Histology and immunohistochemistry of bone sections}

The bone sections were stained by HE staining, toluidine blue staining and Masson's trichrome staining. Three views were randomly selected to evaluate the results of histological staining. 
Immunohistochemical analysis: Bone sections were pretreated with $0.4 \mathrm{mg} / \mathrm{ml}$ Pepsin for 30 minutes at room temperature for optimal antigen retrieval, incubated in $3 \% \mathrm{H} 2 \mathrm{O} 2$ for 10 minutes (protect from light) to remove endogenous peroxidases. Nonspecific staining was blocked with PBS containing $10 \%$ normal sheep serum for 30 minutes at room temperature. A primary anti-mouse monoclonal antibody against rat Type $\varangle$ collagen (1:50) and primary anti-rabbit monoclonal antibody against rat TGF- $\beta 1$ (1:100) was applied to the section which was incubated at $4{ }^{\circ} \mathrm{C}$ for 12 hours and rinsed again with PBS. Rabbit Twostep Test Kit and Mouse Two-step Test Kit (ZSGB-BIO, Beijing) were used to binding IgG polymer, followed immunostaining was detected by Dako REALTM EnVisionTM Detection System(ZSGB-BIO, Beijing). Immunohistochemical staining will be semi-quantitatively scored according to the previously mentioned literature, divided into : $<5 \%(0) ; 5-30 \%(+) ; 31-50 \%(++) ; 51-75 \%(+++)$, and $>75 \%(++++)$ according to the percentage of positive area percentage, divided into: 0 , weak staining $=1$, moderate staining $=2$, strong staining $=3$, very strong staining $=4$ according to the intensity of staining. Percentage and intensity of staining were evaluated by software SPSS 22.0 and Image Pro Plus [28, 29].

\subsection{Modified Mankin's score}

A Modified Mankin's score system was used to evaluate the degree of degeneration of cartilage section [30]. The components for evaluation included: 1 ) cartilage structure $(0-6), 2)$ cartilage cells $(0-3), 3)$ Toluidine blue staining $(0-4), 4)$ tidemark integrity $(0-1)$. The articular cartilage structure was graded on a scale ranging from 0 (normal) to 14 (most severe cartilage injury).

\subsection{ELISA}

The supernatant of each group of co-culture system was tested by using TGF- $\beta 1$ and EGF ELISA Kits (TB healthcare). And synovial fluid removed in animal experiments was detected by TGF- $\beta 1$, EGF, IL-10 and TNF-a, ELISA Kits(TB healthcare) as described in their instructions.

\subsection{Statistical analysis}

SPSS 22.0 (IBM, Armonk, NY, USA) was used for statistical analysis and evaluate the correlation between the various treatments and the experimental results. Factorial analysis and One Way Anova for more than two comparisons of samples; $T$ test was also used to determine the differences between two groups, $p<$ 0.05 was considered significant.

\section{Result}

\subsection{Phenotype and differentiation ability of BMSC.}

BMSCs grew well in the T25 cm2 tissue culture flasks. Cells grew in a typical fusiform morphology and spindle-shaped (Fig. 1A), which is a common form of mesenchymal stem cells [31]. It was found that Oil red $\mathrm{O}$ staining were positive after adipogenic differentiation (Fig. $1 \mathrm{~B}_{1}$ ). And Alizarin red staining was positive after osteogenic differentiation, the calcium nodules were generated (Fig. $\left.1 \mathrm{~B}_{2}\right)$. It indicated that 
BMSCs had good multi-directional differentiation ability. Flow Cytometer showed that BMSCs of passage 3 expressed high levels of double fluorescence CD29 and CD90 on the membrane and expressed low levels of hematopoietic markers CD45(Fig. $1 \mathrm{C}_{1}$ ), CD29 + CD $90+$ CD45- cells purity reached $95 \%$, (Fig. $1 \mathrm{C}_{2}$ ). Newly isolated osteoarthritic chondrocytes were adherent to the six-well plate and then confluence $70 \%$ 80 on the fifth day. Primary chondrocytes showed transparent polygon shape, cytoplasm rich. (Fig. 1D), Toluidine blue staining was used for chondrocyte identification [32, 33], it showed in Fig. 1E that cells stain positive for Toluidine blue (Fig. 1E).

\subsection{BMSCs were undifferentiated in co-culture system but regulated factors level.}

It found that BMSCs cell cultured alone were negative for toluidine blue staining and their morphology was quite different from osteoarthritic chondrocytes, (black arrows, Fig. $2 \mathrm{~A}_{1}$ ). It could select osteoarthritic chondrocytes with positive staining to compare the staining intensity and quantity. It found the staining intensity of osteoarthritic chondrocytes in groups OCs Alone, Direct Co-culture and Indirect Co-culture got $3 \sim 4$ score, which mean that Toluidine blue staining of cell slides were slight reduction or normal on day 3. And these three group was not significant different. But on the day 7 ,the staining intensity of osteoarthritic chondrocytes in group Direct Co-culture were higher than the other two group (Fig. $2 \mathrm{~A}_{2}$ ). On day 3 and day 7 , three random visions of OCs Alone, Direct Co-culture and Indirect Coculture were randomly select to count the number of cells. We found that the average number of cells in group Direct Co-culture and Indirect Co-culture were significantly higher than that in group OCs Alone(Fig. $2 \mathrm{~A}_{3}$ ). Furthermore, Trap staining was showed negative in each group (Fig. 2B). Alizarin red has no positive staining in each group, there was not abnormal calcium accumulation in each group (Fig. 2C). It mean that BMSCs co-culture with OCs did not cause their differentiation into osteoblasts or osteoclasts.

It showed that TGF- $\beta 1$ detected in group BMSCs Alone, Direct Co-culture and Indirect Co-culture and it peaked on the day 3 and fell in the following time, and there was high concentrations of TGF- $\beta 1$ can be detected in group BMSCs Alone during all its culture periods; while Direct Co-culture and Indirect Coculture can only detect trace on days 2 to 4 . But in group OCs Alone, no TGF- $\beta 1$ concentration was detected (Fig. 2D). Conversely, it was found that EGF can be detected in group OCs Alone, Direct Coculture and Indirect Co-culture but not in group BMSCs Alone, EGF continues to increase in these three group during the cultivation period, and on day 7 , the highest EGF concentration was detected in Direct Co-culture ( Fig. 2E, p< 0.05).

\subsection{BMSCs delay cartilage degradation, delay fibrosis and inhibit intra-articular inflammation}

As showed in Fig. 3, histological staining and immunohistochemistry of Normal were used as references. After treatment regime, HE staining result showed that BMSC-injected had the best cartilage tissues appearance and intact tideline at all periods, and cartilage tissues and intact tideline was both destroyed 
in Supernatant-injected and Control at 8 weeks $\left(\right.$ Fig. $\left.3 \mathrm{~A}_{1}\right)$; To evaluate the proteoglycan content (glycosaminoglycan) of articular cartilage in the studied groups, Toluidine blue staining was performed[34]. Toluidine blue staining showed that cartilage tissue of all groups had different degrees of reduction. In 6 weeks, Toluidine blue staining showed more cartilage tissues were present in BMSCinjected and Supernatant-injected but less in Control, And at 8 weeks, group BMSC-injected had the largest range of cartilage tissue than the other two groups $\left(\mathrm{Fig} .3 \mathrm{~A}_{2}\right)$. Masson trichrome staining was evaluated the fibrosis of joints after treatment. It found that all groups inevitably produced progressive fibrosis of articular cartilage during OA progression except Normal. Before 6 weeks the degree of joint fibrosis of BMSCs-injected was significantly lighter than that in Supernatant-injected and Control, But, at 8 weeks, there was no significant difference among the three groups ( $\mathrm{Fig} .3 \mathrm{~A}_{3}$ ). The Modified Mankin scores was obtained from above three histology staining. Compared with the Control and Supernatantinjected, the BMSC-injected was significantly decreased the Modified Mankin score in all periods, Supernatant-injected also reduced the Modified Mankin score but not as significantly as BMSC-injected $\left(p<0.05\right.$, Fig. $\left.3 A_{4}\right)$. This indicates that injection of BMSCs was significantly better than injection of PBS or Supernatant for OA treatment.

The Type I collagen and TGF- $\beta 1$ changes in the cartilage layer were evaluated from Immunohistochemistry. It used Image Pro Plus software to compare the staining intensity where the area above the black arrow(Cartilage layer)(Fig. 3B ${ }_{1}, C_{1}$ ), and uses SPSS22.0 software to quantitatively compare the quantified positive staining range percentage (Fig. $3 \mathrm{~B}_{2}, \mathrm{C}_{2}$ ). And it got a table to semiquantitatively evaluate (Table 2). The results showed that staining intensity of type I collagen was absent staining in all periods of Normal(Fig. $\left.3 \mathrm{~B}_{1}\right)$. In the sixth week and eighth week after treatment, The ES of Control (IS = 2; $E S=++, P \Downarrow 0.01)$ and Supernatant-injected (IS = 2; $E S=++, P \otimes 0.01$ ) were both more lager compared with that in BMSCs-injected $(I S=1, E S=+) \square F i g .3 B_{2} \rrbracket$. It indicated that type I collagen also has abnormal increased expression in the long-term disorder of OA and BMSCs can reduce the production of this type of collagen within eight weeks after being injected. The Fig. $3 \mathrm{C}_{1}$ showed that staining intensity of TGF- $\beta 1$ was absent staining in all periods of Normal as well. In the Immunohistochemistry assay of other three groups, TGF- $\beta 1$ staining changes were mainly focused on superficial and intermediate cartilage rather than deep tissue $\left(\right.$ Fig. $\left.3 C_{1}\right)$. At the fourth week, the ES of Supernatant-injected $(I S=1 / 2$; $\mathrm{ES}=+, \mathrm{P} \unrhd 0.05)$ and $\mathrm{BMSCs}$-injected $(\mathrm{IS}=1 ; \mathrm{ES}=+, \mathrm{P} \otimes 0.01)$ were less than that in Control $(\mathrm{IS}=3$; $\mathrm{ES}=$ $+/++)$, At the sixth week the ES of BMSC(IS = 2;ES = +, Pख0.01) were lower than that in Control(IS = 3/4; ES $=+/++, P \otimes 0.01)$ and Supernatant-injected $(I S=2 / 3 ; E S=+/++)\left(F i g .3 C_{2}\right)$. This suggested that the longterm wear of cartilage tissue can stimulate the increased of TGF- $\beta 1$ in the matrix, while the injection of BMSCs can reduce the concentration of TGF- $\beta 1$ in cartilage layer.

It examined changes in the concentration of EGF and TGF $\beta 1$ in synovial fluid of each group. As showed in Fig. $3 \mathrm{D}_{1}$, the concentration of TGF- $\beta 1$ detected in the synovial fluid of the Normal group was lower than the lowest detection concentration of the kit. At 4 weeks, we found that the concentration of TGF- $\beta 1$ in groups of Control, Supernatant-injected and BMSCs-injected was $19.79 \pm 0.44 \mathrm{pg} / \mathrm{ml}, 19.31 \pm 0.29 \mathrm{pg} / \mathrm{ml}$, $18.58 \pm 0.25 \mathrm{pg} / \mathrm{ml}$. And, at 6 weeks, the concentration was $20.57 \pm 1.10 \mathrm{pg} / \mathrm{ml}, 20.89 \pm 1.26 \mathrm{pg} / \mathrm{ml}, 18.32$ 
$\pm 0.68 \mathrm{pg} / \mathrm{ml}$. the concentration of TGF- $\beta 1$ in BMSCs-injected was significantly lower than that in Control and Supernatant-injected at 4 weeks and 6 weeks $\left(p<0.05\right.$, Fig. $\left.3 D_{1}\right)$. At 8 weeks, there was no significant difference in the concentration of TGF- $\beta 1$ compare groups with each other; In contrast, the concentration of EGF factor can be detected in the synovial fluid of each group, and the Normal was much higher than the other three groups. It found that the concentration of EGF in BMSCs-injected was higher than the Control at 4 weeks and 6 weeks, $\left(p<0.05\right.$, Fig. $\left.3 D_{2}\right)$. And the concentration of EGF in Supernatant-injected was higher than Control and lower than BMSCs-injected in all periods, but it was no significant compared with the other two groups. At 8 weeks, there was no significant difference between the three groups. It examined changes in the concentration of IL-10 and TNF-a in synovial fluid after different treatments as well. Due to the difference of experimental individuals, simple factor changes are not sufficient to represent the direction of inflammatory changes in the joints, so we introduce IL-10/TNFa ratios to assess the direction of verification. For IL-10, at 4 weeks, Control, Supernatant-injected and BMSCs-injected were $23.71 \pm 2.30 \mathrm{pg} / \mathrm{ml}, 28.47 \pm 1.78 \mathrm{pg} / \mathrm{ml}, 28.30 \pm 3.95 \mathrm{pg} / \mathrm{ml}$ respectively. At 6 weeks, they were $25.25 .20 \pm$ $2.25 \mathrm{pg} / \mathrm{ml}, 25.65 \pm 1.39 \mathrm{pg} / \mathrm{ml}, 32.94 \pm 2.89 \mathrm{pg} / \mathrm{ml}$ respectively. At 8 weeks, they were $21.36 \pm 1.24 \mathrm{pg} / \mathrm{ml}$, $22.30 \pm 0.88 \mathrm{pg} / \mathrm{ml}, 25.25 \pm 1.89 \mathrm{pg} / \mathrm{ml}$ respectively; For TNF-a, at 4 weeks, the concentration of TNF- $\mathrm{a}$ in Control, Supernatant-injected and BMSC-injected was $163.60 \pm 5.26 \mathrm{pg} / \mathrm{ml}, 165.74 \pm 2.88 \mathrm{pg} / \mathrm{ml}, 135.47 \pm$ $12.36 \mathrm{pg} / \mathrm{ml}$ respectively. At 6 weeks, they were $177.98 \pm 3.94 \mathrm{pg} / \mathrm{ml}, 174.84 \pm 8.84 \mathrm{pg} / \mathrm{ml}, 129.19 \pm$ $8.19 \mathrm{pg} / \mathrm{ml}$ respectively. At 8 weeks, they were $220.65 \pm 17.17 \mathrm{pg} / \mathrm{ml}, 216.24 \pm 15.53 \mathrm{pg} / \mathrm{ml}, 177.30 \pm$ $13.67 \mathrm{pg} / \mathrm{ml}$ respectively. From the above data, it drawn the IL-10/TNFa ratios chart in Fig. $3 \mathrm{D}_{3}$. we can found that, in the Normal group, the IL-10/TNFa ratios were higher than the other three groups in all periods, it maintain a stable anti-inflammatory environment. At 4 weeks, the IL-10/TNFa ratios of the Supernatant-injected and BMSC-injected were higher than that of the Control(p $\otimes 0.01$, Fig. 3D $\mathrm{D}_{3}$ ). At 6 and 8 weeks, the BMSC-injected was higher than the Supernatant-injected and Control, and there was no

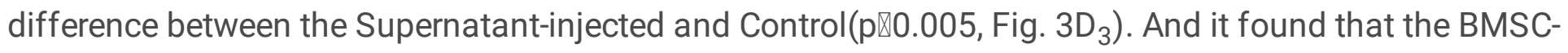
injected had the highest ratio at 6 weeks, but it declined at 8 weeks $\left(\right.$ Fig. $\left.3 D_{3}\right)$, This shown that the injection of supernatant and BMSCs can promote the anti-inflammatory effect within 4 weeks, but only the injection of BMSCs can be maintained until the 8 weeks, and this effect reached the highest ratio at 6 weeks, and then began to decline. 
Table 2

Semi-quantitative scoring of TGF- $\beta 1$ levels and Type 1 collagen immunostaining.

\begin{tabular}{|c|c|c|c|c|}
\hline \multirow[t]{2}{*}{ group } & \multicolumn{4}{|c|}{$\begin{array}{l}\text { Intensity of Immune Staining (IS) and Percentage of Immuneopositive Area (Extent } \\
\text { Score=ES) }\end{array}$} \\
\hline & 4 weeks & 6 weeks & 8 weeks & Immunostaining \\
\hline Control & $\begin{array}{l}\text { Weak/absent } \\
\text { immunostaining } \\
(I S=1 ; E S=+)\end{array}$ & $\begin{array}{l}\text { Weak/ moderate } \\
\text { immunostaining } \\
(I S=2 ; E S=++)\end{array}$ & $\begin{array}{l}\text { Weak/moderate } \\
\text { immunostaining }(I S= \\
2 ; E S=++)\end{array}$ & \multirow[t]{3}{*}{ Type Icollagen } \\
\hline Supernatant & $\begin{array}{l}\text { Weak/absent } \\
\text { immunostaining } \\
(I S=1 ; E S=+)\end{array}$ & $\begin{array}{l}\text { Weak/ moderate } \\
\text { immunostaining } \\
(I S=2 ; E S=++)\end{array}$ & $\begin{array}{l}\text { Weak / moderate } \\
\text { immunostaining (IS = } \\
2 ; \mathrm{ES}=++)\end{array}$ & \\
\hline BMSC & $\begin{array}{l}\text { Weak/absent } \\
\text { immunostaining } \\
(I S=1 ; E S=+)\end{array}$ & $\begin{array}{l}\text { Weak/absent } \\
\text { immunostaining } \\
(I S=1 ; E S=+)\end{array}$ & $\begin{array}{l}\text { Weak/immunostaining } \\
(I S=1 ; E S=+)\end{array}$ & \\
\hline Control & $\begin{array}{l}\text { Very strong } \\
\text { immunostaining } \\
(I S=3 ; E S=+/++)\end{array}$ & $\begin{array}{l}\text { Very strong } \\
\text { immunostaining } \\
(\mathrm{IS}=3 / 4 ; \mathrm{ES}= \\
+/++)\end{array}$ & $\begin{array}{l}\text { Moderate/ strong } \\
\text { immunostaining } \\
(\mathrm{IS}=2 ; \mathrm{ES}=+)\end{array}$ & \multirow[t]{3}{*}{ TGF- $\beta 1$} \\
\hline Supernatant & $\begin{array}{l}\text { Strong/moderate } \\
\text { immunostaining } \\
(\mathrm{IS}=1 / 2 ; \mathrm{ES}=+)\end{array}$ & $\begin{array}{l}\text { strong } \\
\text { immunostaining } \\
(I S=2 / 3 ; E S= \\
+/++)\end{array}$ & $\begin{array}{l}\text { Moderate/ strong } \\
\text { immunostaining } \\
(\mathrm{IS}=2 ; \mathrm{ES}=+)\end{array}$ & \\
\hline BMSC & $\begin{array}{l}\text { Moderate/ strong } \\
\text { immunostaining } \\
(I S=1 ; E S=+)\end{array}$ & $\begin{array}{l}\text { Moderate/strong } \\
\text { immunostaining } \\
(\mathrm{IS}=2 ; \mathrm{ES}=+)\end{array}$ & $\begin{array}{l}\text { Moderate/ strong } \\
\text { immunostaining } \\
(\mathrm{IS}=2 ; \mathrm{ES}=+)\end{array}$ & \\
\hline $\begin{array}{l}\text { Note: It used I } \\
\text { black arrow, in } \\
\text { following ass } \\
\text { compare the } \\
50 \%(++) ; 51-\end{array}$ & $\begin{array}{l}\text { sment: 0, no detec } \\
\text { antified positive } s \\
5 \%(+++) \text {, and }>75\end{array}$ & $\begin{array}{l}\text { e to compare the } \\
\text { ining = IS)was gra } \\
\text { le staining; and u } \\
\text { ing area percenta } \\
++++) \text {. }\end{array}$ & $\begin{array}{l}\text { hing intensity where the } \\
\text { lon a scale of } 0-4 \text {, acco } \\
\text { SPSS22.0 software to } q \\
\text { Extent Score = ES): }<5 \%\end{array}$ & $\begin{array}{l}\text { ea above the } \\
\text { ing to the } \\
\text { antitatively } \\
\text { ); 5-30\% }(+) ; 31-\end{array}$ \\
\hline
\end{tabular}

\section{Discussion}

\subsection{The therapeutic function of BMSCs cannot be replaced by its culture supernatant}

BMSCs therapy is a potential option for OA treatment, provides a substitute way for autologous MSCs that may have been affected by OA injury [35].Mesenchymal stem cells (MSCs) possessed well differentiation capacity, anti-inflammatory and regenerative functions, and were typically used for OA treatment [36]. BMSCs was an excellent cell which was more proliferative and differentiated than MSCs from other sources [37], and previous studies have shown that allogeneic BMSCs do not induce any adverse local or systemic response [38]. 
In our co-culture system, the osteoarthritic chondrocytes would be co-cultured with BMSCs to mimic the cell treatment process. In our animal design, after total medial meniscectomy and ACLT to induce OA model, in vitro expanded culture of allogeneic BMSCs and its cultured supernatant were respectably injected into the joint cavity. And In our study, there were no substances or scaffold be used to exclude other interference, thereby, it accurately simulates the process of BMSCs in contact with articular chondrocytes after injection. In our co-culture system, we found that BMSCs did not differentiate into chondrocytes when BMSCs are direct cell-cell cultured with osteoarthritic chondrocytes. We used a similar method to evaluate chondrocytes $[39,40]$. We found that when BMSCs were directly co-cultured with OCs, they could delay the loss of OCs cytoplasm on the 7th day, and there was no such obvious effect when they were not directly contacted., And whether it is exposed or not, it can promote the proliferation of chondrocytes, which may be achieved by adjusting the concentration of cytokines in the culture medium. Moreover, after 7 days of co-cultivation of BMSCs, no positive staining of BMSCs cells to osteoblasts, osteoclasts or chondrocytes was found. Although there are literatures indicating that BMSCs have a tendency to differentiate into chondrocytes during OA treatment, In our experimental results, BMSCs did not differentiate into cartilage within 7 days, This showed that the differentiation of BMSCs did not play a major function in the early stage of treatment but mainly through contact with chondrocytes to delay chondrocyte cytoplasmic substance loss, and to regulate cartilage proliferation by factors in the culture medium.

After treatment with BMSCs, we found that the Modified Mankin score was lower in BMSCs-injected compared to the Control. But it does not show statistical between Supernatant-injected and Control, although the average value of the Modified Mankin score of Supernatant-injected appeared were lower than that of the Control group. It also found that the glycosaminoglycan of osteoarthritic chondrocytes were protected when osteoarthritic chondrocytes were direct co-cultured with BMSCs. Corresponding, the cartilage sections of the BMSCs-injected possessed the smoothest superficial cartilage, with the least loss of glycosaminoglycan, and the most complete cartilage tissue. Meanwhile, BMSCs can prevent fibrosis of joints. Compared with the other two groups, Masson's trichrome staining of BMSCs-injected was closer to normal. As previously study described, Type I collagen was increased in OA joint due to the lost joint range of motion [41]. This research was found the same result. In the Normal, type I collagen was hardly appeared in cartilage surface, which was increased in cartilage surface in the other three groups. And type I collagen staining with the least range and lowest intensity was found in group BMSCsinjected compare with Control and Supernatant-injected at the same period. The result of immunohistochemical showed that BMSCs therapy can decrease type I collagen expression. In short, BMSCs therapy protected cartilage, reduced the abnormal differentiation and proliferation and fibrosis in the knee articular cartilage, thus slow down the process of cartilage degradation. BMSCs cell therapy reduced cartilage degradation and decreased Modified Mankin score. The function of BMSCs required contact with chondrocytes, and the regulation of cytokines also required its presence, it mean the therapeutic function of BMSCs cannot simply be replaced by its culture supernatant.

\subsection{BMSCs reduce TGF- $\beta 1$ level and increase EGF level during $\mathrm{OA}$.}


TGF- $\beta 1$, which is abundant in the bone matrix but little in normal joint synovial fluid [42, 43], is a ubiquitous multi-functional cytokine that regulates the proliferation, differentiation and production of extracellular matrix of various biological tissues [44]. While the knee joint was slightly abrasion TGF- $\beta 1$ was stimulated to secreted from bone matrix to maintain healthy joint tissues and recruitment of BMSCs to the bone remodeling surfaces in the coupling process and promoting cartilage formation [42, 45], But there was another point suggest that high levels of active TGF- $\beta 1$ has been shown to induce pathological effects associated with osteoarthritis, such as inflammation, synovial fibrosis, and the formation of osteophytes [46]. BMSCs had two-sided regulation of TGF- $\beta 1$. In co-culture system, we can found that separate culture BMSCs secreted TGF- $\beta 1$ to enhance self-proliferation $(p<0.05$, Fig. 2D). But when BMSCs co-cultured with osteoarthritic chondrocytes, BMSCs were stimulated by chondrocytes with inflammatory phenotype to stimulate their inhibitory effects on TGF $\beta 1$. It can be observed that BMSCs reduce the concentration of GF $\beta 1$ in the supernatant of co-culture system. In animal experiments, we also observed a similar pathological process. TGF- $\beta 1$ was stimulated to secrete from bone matrix caused by joint wear. In the bone tissue section at week 4 , it can be seen that high concentration of TGFB1 leads to abnormal increase in the cartilage layer (Fig. 3A2). In the BMSCs injection treatment group, the high concentration of TGFB1 and inflammation levels in the joints activated the regulation of BMSCs, and the concentration of GF $\beta 1$ in the synovial fluid decreased. However, injection-treated BMSCs do not survive long in vivo [18], Therefore, it has a more obvious therapeutic effect only in the first 6 weeks. Therefore, an elevated TGF $\beta$ concentration was detected at 8 weeks.

Osteoarthritic chondrocytes had been shown to have EGF expression, and it has been shown that EGF was related to its growth and proliferation [47]. EGF was indeed a general growth factor exerting various actions including cell migration and proliferation in a wide variety of cells [48]. In this co-culture system, except for BMSCs Alone, EGF was detected in the culture supernatant of the other three groups. The highest concentration was detected in Direct Co-culture at day 7 , and there was no significant difference between OCs Alone and Indirect Co-culture. Considering the differences in culture methods, it found that the difference was Direct Co-culture had the cell-to-cell contact between BMSCs and OCs. Therefore, it had reason to believe that cell -to-cell contact play an important way to exert their function. BMSCs can enhance the regulation of chondrocytes on EGF levels. As previous studies had shown, EGF was naturally present in joint synovial fluid[48], and EGF maintained the superficial layer of articular cartilage [14]. In this animal experiment, EGF concentration was detected in all groups. The concentration of EGF was highest in the Normal, This indicates that the concentration of EGF in the OA synovial fluid is reduced compared to normal joint synovial fluid. However, after different types of therapeutic intervention, we can detect the highest concentration of EGF in BMSCs-injected group. This indicated that the injection of BMSCs can regulate the concentration of EGF in the joint cavity. BMSCs do not directly secrete EGF to regulate, but maintain the normal phenotype of chondrocytes and increase the concentration of EGF in the joint cavity. Furthermore, MSCs possess EGF receptors that respond to soluble EGF [49], and EGF stimulates MSCs proliferation without altering differentiation process and potentials [50]. And EGF does not cause abnormal differentiation of BMSCs. Therefore, it can be considered that BMSCs cell therapy is not only safe, but is actually a synergy between the two cells. 


\subsection{BMSCs inhibit intra-articular inflammation to protect articular cartilage regeneration.}

TNF- $\alpha$ and IL-10 were the typical pro-inflammatory and anti-inflammatory markers respectively $[19,20]$. It recognized that IL-10 level was low in the synovial fluid of OA [51]. IL-10 can suppress inflammation and accelerates healing [52-54]. TNF-a was a typical pro-inflammatory factor and its abnormal elevations were usually associated with loss of proteoglycan [55]. Normal joint activity causes joint wear and increases TNF- $a$ secreted by the cartilage matrix stimulated [56], and it can enhance the expression of matrix metalloproteinase, which cause excessive degradation of the cartilage matrix and it led to increased levels of inflammation [20]. The inflammation level in each joint was different, this mean the absolute amounts of pro-inflammatory and anti-inflammatory factors were not consistent. So the IL10/TNF-a ratios were used to evaluate the balance between pro-inflammatory and anti-inflammatory factor and clarify the direction of changes in the inflammation balance [57]. As shown in the above data, the IL-10/TNF-a ratio of the Normal group was significantly higher than that of the other three groups, this indicated that the wear and tear of daily activities leads to slight inflammation of the joints. IL-10 is activated by this slight inflammation and increases expression in joints, which results in Inhibit inflammation in joints and tend to a kind of inflammatory balance. But this inflammatory balance was broken in the knee joint of OA. Although the absolute amount of the anti-inflammatory factor IL-10 was increasing during the progression of $\mathrm{OA}$, the inflammatory factor TNF-a was also greatly increased. The final result was that it leads to IL10 / TNF-a ratio decline, the intra-articular inflammation was further exacerbated and caused joint destruction. BMSCs were a kind of cell that can regulate pro-inflammatory and anti-inflammatory factors [13]. In this study, it found that BMSCs main exerted their antiinflammatory effects on the treatment of OA. As revealed in Fig. $3 \mathrm{D}_{3}$, the IL-10/TNF-a ratio of Supernatant-injected was higher than the Control at 4 weeks. This may be due to the presence of antiinflammatory factors in the BMSCs culture supernatant. This shown that the effect of this supernatant injection treatment can be maintained for about only 4 weeks. The IL-10/TNF-a ratios of BMSCs-injected were higher than the Supernatant-injected and Control in all periods, and the highest IL-10/TNF-a ratio was found at 6 weeks. There was a study shown that BMSCs by exogenous injected cannot survive for a long time in vivo [18]. So it found the ratio dropped at 8 weeks. This shown that the effect of these cells injection treatment can be maintained for about 8 weeks. In terms of cartilage matrix, proteoglycan was a matrix substance sensitive to inflammation. We only observed good cartilage matrix proteoglycan content in the 4 and 6 week bone sections of the BMSCs-injected. Therefore, the inhibitory effect of BMSCs on inflammation was an extremely important part in the treatment of OA. Although its culture supernatant also had an inhibitory effect on inflammation in the early stage of treatment, this ability of regulate inflammation cannot be replaced by its culture supernatant.

In summary, BMSCs therapy can inhibit intra-articular inflammation, reduce intra-articular inflammatory infiltration and delay joint degeneration, and provide a good environment for cartilage self-healing and maintain proteoglycan in its cytoplasm. This cell therapy was very safe. Looking forward to this therapy, 
in order to maintain the continuous anti-inflammatory effect of BMSCs, continuous injection at intervals of 6 weeks may become a feasible treatment plan in the future.

\section{Conclusion}

In conclusion, the present experiments indicated that growth and inflammatory factors play a very important role in protecting the joints from degeneration. Disturbance of factor levels in joint synovial fluid and uncontrolled inflammation regulation accelerate joint degeneration. BMSCs therapy was a very potential new therapy can truly delay joint degeneration and reduce the loss of cell matrix and proteoglycan in the articular cartilage layer. And it indicated that the early stage of BMSCs injection into the joint cavity was due to its role in reducing the abnormal increase of TGF- $\beta$ in joint synovial fluid and joint matrix, increase the concentration of EGF in joint synovial fluid, and inhibit inflammation in joint cavity. In addition, despite the presence of multiple growth factors and inflammatory factors in the BMSCs culture supernatant, the injection therapy of BMSCs culture supernatant cannot replace the BMSCs for more durable and precise regulation.

\section{Abbreviations}

OA, Osteoarthritis; BMSCs, Bone marrow mesenchymal stem cells; ACLT, Anterior cruciate ligament transection; OCs, osteoarthritic chondrocytes.

\section{Declarations}

\section{Ethics approval and consent to participate}

Ethics approval ,the In vivo experiment of this article was approved by the Animal Experimental Center, Southern Medical University, Guangzhou, Guangdong, China.

\section{Consent for publication}

Not applicable.

\section{Availability of data and materials}

Please contact author for data requests.

\section{Conflicting interests}

The authors declare that they have no competing interests.

\section{Funding}

This work was supported by the National Natural Science Foundation of China [NSFC, 201610010174]; and Guangdong Provincial Higher Education Excellent Young Teacher Training Program Funding Project 
of China [YQ2015040].

\section{Contributions}

Yiqi Peng, Rui Zhao, Sheng Huang and Shilin Xiong have made a lot of contributions in this work. Anmin Jin were responsible for performing the analyzing of the data. Rui Zhao was responsible for drafting the manuscript. All authors read and approved the final manuscript.

\section{Acknowledgments}

The authors thank the Dpartment of Biochemistry and Molecular Biology, School of Basic Medical Sciences, Southern Medical University, Guangzhou, PR China provide experimental environment and Rui Zhao, who help me a lot during this research..

\section{Author information}

\section{Author notes}

Yiqi Peng and Rui Zhao are co-first authors.

\section{Affiliations}

${ }^{1}$ Department of Spine surgery, Zhujiang Hospital, Southern Medical University, Guangzhou, PR China, 510282.

${ }^{2}$ Orthopaedic surgery, The people's Hospital of Henan province, Zhengzhou, PR China,450003.

${ }^{3}$ Dpartment of Biochemistry and Molecular Biology, School of Basic Medical Sciences, Southern Medical University, Guangzhou, PR China, 510515.

${ }^{4}$ Dept Urol, Zhujiang Hospital, Southern Medical University, Guangzhou, PR China, 510282.

${ }^{5}$ Key Laboratory of Aged Infection and Organ Function Support, General Hospital of Southern Theater, Guangzhou 510010.

\section{Corresponding authors}

Correspondence to Anmin Jin or Zhenghong Yu.

\section{References}

1. Qin J, Theis KA, Barbour KE, et al. Impact of arthritis and multiple chronic conditions on selected life domains - United States, 2013. MMWR Morb Mortal Wkly Rep. 2015;64(21):578-82.

2. Loeser RF. Aging processes and the development of osteoarthritis. Curr Opin Rheumatol. 2013;25(1):108-13. 
3. Berenbaum F. Osteoarthritis as an inflammatory disease (osteoarthritis is not osteoarthrosis!). Osteoarthritis Cartilage. 2013;21(1):16-21.

4. Aigner T, Sachse A, Gebhard PM, et al. Osteoarthritis: pathobiology-targets and ways for therapeutic intervention. Adv Drug Deliv Rev. 2006;58(2):128-49.

5. Pereira D, Ramos E, Branco J. Osteoarthritis Acta Med Port. 2015;28(1):99-106.

6. Xie F, Kovic B, Jin X, et al. Economic and Humanistic Burden of Osteoarthritis: A Systematic Review of Large Sample Studies. Pharmacoeconomics. 2016;34(11):1087-100.

7. Abraham NS, El-Serag HB, Hartman C, et al. Cyclooxygenase-2 selectivity of non-steroidal antiinflammatory drugs and the risk of myocardial infarction and cerebrovascular accident. Aliment Pharmacol Ther. 2007;25(8):913-24.

8. Gracitelli GC, Moraes VY, Franciozi CE, et al. Surgical interventions (microfracture, drilling, mosaicplasty, and allograft transplantation) for treating isolated cartilage defects of the knee in adults. Cochrane Database Syst Rev. 2016;9:CD010675.

9. Gupta PK, Das AK, Chullikana A, et al. Mesenchymal stem cells for cartilage repair in osteoarthritis. Stem Cell Res Ther. 2012;3(4):25.

10. Zhang $\mathrm{Y}$, Chen $\mathrm{H}$, Zhang $\mathrm{T}$, et al. Injectable hydrogels from enzyme-catalyzed crosslinking as BMSCsladen scaffold for bone repair and regeneration. Mater Sci Eng C Mater Biol Appl. 2019;96:841-9.

11. Li W, Xu R, Huang J, et al. Treatment of rabbit growth plate injuries with oriented ECM scaffold and autologous BMSCs. Sci Rep. 2017;7:44140.

12. Zhou LN, Cui XJ, Su KX, et al. Beneficial reciprocal effects of bone marrow stromal cells and Schwann cells from adult rats in a dynamic coculture system in vitro without intercellular contact. Mol Med Rep. 2015;12(4):4931-8.

13. Ma S, Xie N, Li W, et al. Immunobiology of mesenchymal stem cells. Cell Death Differ. 2014;21(2):216-25.

14. Jia $H, M a X$, Tong W, et al. EGFR signaling is critical for maintaining the superficial layer of articular cartilage and preventing osteoarthritis initiation. Proc Natl Acad Sci U S A. 2016;113(50):14360-5.

15. Crane JL, Cao X. Bone marrow mesenchymal stem cells and TGF-beta signaling in bone remodeling. J Clin Invest. 2014;124(2):466-72.

16. Hussein MR, Fathi NA, El-Din AM, et al. Alterations of the CD4(+), CD8 (+) T cell subsets, interleukins1 beta, IL-10, IL-17, tumor necrosis factor-alpha and soluble intercellular adhesion molecule-1 in rheumatoid arthritis and osteoarthritis: preliminary observations. Pathol Oncol Res. 2008;14(3):3218.

17. Wojdasiewicz P, Poniatowski LA, Szukiewicz D. The role of inflammatory and anti-inflammatory cytokines in the pathogenesis of osteoarthritis. Mediators Inflamm. 2014;2014:561459.

18. Li M, Luo X, Lv X, et al. In vivo human adipose-derived mesenchymal stem cell tracking after intraarticular delivery in a rat osteoarthritis model. Stem Cell Res Ther. 2016;7(1):160. 
19. Kim JE, Lee SM, Kim SH, et al. Effect of self-assembled peptide-mesenchymal stem cell complex on the progression of osteoarthritis in a rat model. Int J Nanomedicine. 2014;9(Suppl 1):141-57.

20. Lai Y, Bai X, Zhao Y, et al. ADAMTS-7 forms a positive feedback loop with TNF-alpha in the pathogenesis of osteoarthritis. Ann Rheum Dis. 2014;73(8):1575-84.

21. Ouyang X, Wang J, Hong SD, et al. Establishment of a rat model for osteoarthritis resulting from anterior cruciate ligament rupture and its significance. Exp Ther Med. 2015;10(6):2035-8.

22. Chen X, Wang J, Yu L, et al. Effect of Concentrated Growth Factor (CGF) on the Promotion of Osteogenesis in Bone Marrow Stromal Cells (BMSC) in vivo. Sci Rep. 2018;8(1):5876.

23. Kong Y, Guo Y, Zhang J, et al. Strontium Promotes Transforming Growth Factors beta1 and beta2 Expression in Rat Chondrocytes Cultured In Vitro. Biol Trace Elem Res. 2018;184(2):450-5.

24. Han G, Shao $H$, Zhu X, et al. The protective effect of xanthan gum on interleukin-1beta induced rabbit chondrocytes. Carbohydr Polym. 2012;89(3):870-5.

25. Qing C, Wei-ding C, Wei-min F. Co-culture of chondrocytes and bone marrow mesenchymal stem cells in vitro enhances the expression of cartilaginous extracellular matrix components. Braz $\mathrm{J}$ Med Biol Res. $2011 ; 44(4): 303-10$.

26. Levorson EJ, Santoro M, Kasper FK, et al. Direct and indirect co-culture of chondrocytes and mesenchymal stem cells for the generation of polymer/extracellular matrix hybrid constructs. Acta Biomater. 2014;10(5):1824-35.

27. Zuo Q, Cui W, Liu F, et al. Co-cultivated mesenchymal stem cells support chondrocytic differentiation of articular chondrocytes. Int Orthop. 2013;37(4):747-52.

28. Yu Y, Huang R, Zong X, et al. INFalpha-2b inhibitory effects on CD4(+)CD25(+)FOXP3(+) regulatory $T$ cells in the tumor microenvironment of C57BL/ $6 \mathrm{~J}$ mice with melanoma xenografts. BMC Cancer. 2016;16:397.

29. Giunta S, Castorina A, Marzagalli R, et al. Ameliorative effects of PACAP against cartilage degeneration. Morphological, immunohistochemical and biochemical evidence from in vivo and in vitro models of rat osteoarthritis. Int J Mol Sci. 2015;16(3):5922-44.

30. Kuroki H, Nakagawa Y, Mori K, et al. Acoustic stiffness and change in plug cartilage over time after autologous osteochondral grafting: correlation between ultrasound signal intensity and histological score in a rabbit model. Arthritis Res Ther. 2004;6(6):R492-504.

31. Li H, Yu S, Hao F, et al. Insulin-like growth factor binding protein 4 inhibits proliferation of bone marrow mesenchymal stem cells and enhances growth of neurospheres derived from the stem cells. Cell Biochem Funct. 2018;36(6):331-41.

32. Sridharan G, Shankar AA. Toluidine blue: A review of its chemistry and clinical utility. J Oral Maxillofac Pathol. 2012;16(2):251-5.

33. Pei Y, Fan JJ, Zhang XQ, et al. Repairing the osteochondral defect in goat with the tissue-engineered osteochondral graft preconstructed in a double-chamber stirring bioreactor. Biomed Res Int. 2014;2014:219203. 
34. Jacer S, Shafaei H, Rad JS. An Investigation on the Regenerative Effects of Intra Articular Injection of Co-Cultured Adipose Derived Stem Cells with Chondron for Treatment of Induced Osteoarthritis. Adv Pharm Bull. 2018;8(2):297-306.

35. Vega A, Martin-Ferrero MA, Del Canto F, et al. Treatment of Knee Osteoarthritis With Allogeneic Bone Marrow Mesenchymal Stem Cells: A Randomized Controlled Trial. Transplantation. 2015;99(8):1681-90.

36. Sheykhhasan M, Manoochehri H, Pourjafar $M$, et al. Mesenchymal stem cells as a valuable agent in osteoarthritis treatment. Stem Cell Investig. 2018;5:41.

37. Afizah $\mathrm{H}$, Yang Z, Hui JH, et al. A comparison between the chondrogenic potential of human bone marrow stem cells (BMSCs) and adipose-derived stem cells (ADSCs) taken from the same donors. Tissue Eng. 2007;13(4):659-66.

38. Le Blanc K, Tammik C, Rosendahl K, et al. HLA expression and immunologic properties of differentiated and undifferentiated mesenchymal stem cells. Exp Hematol. 2003;31(10):890-6.

39. von der Mark K, Gauss V, von der Mark H, et al. Relationship between cell shape and type of collagen synthesised as chondrocytes lose their cartilage phenotype in culture. Nature. 1977;267(5611):5312.

40. Aung A, Gupta G, Majid G, et al. Osteoarthritic chondrocyte-secreted morphogens induce chondrogenic differentiation of human mesenchymal stem cells. Arthritis Rheum. 2011;63(1):14858.

41. Campbell TM, Reilly K, Laneuville 0 , et al. Bone replaces articular cartilage in the rat knee joint after prolonged immobilization. Bone. 2018;106:42-51.

42. Tang $Y, W u X$, Lei $W$, et al. TGF-beta1-induced migration of bone mesenchymal stem cells couples bone resorption with formation. Nat Med. 2009;15(7):757-65.

43. Hering $S$, Isken E, Knabbe $C$, et al. TGFbeta 1 and TGFbeta 2 mRNA and protein expression in human bone samples. Exp Clin Endocrinol Diabetes. 2001;109(4):217-26.

44. Zhang WQ, Gu GX, Xia Q, [Interactions between transforming growth factor beta and signal transducer and activator of transcription 3 in the development of liver fibrosis]. Zhonghua Gan Zang Bing Za Zhi, 2018. 26(10): p. 792-796.

45. Albro MB, Cigan AD, Nims RJ, et al. Shearing of synovial fluid activates latent TGF-beta. Osteoarthritis Cartilage. 2012;20(11):1374-82.

46. van Beuningen $\mathrm{HM}$, van der Kraan PM, Arntz OJ, et al. Transforming growth factor-beta 1 stimulates articular chondrocyte proteoglycan synthesis and induces osteophyte formation in the murine knee joint. Lab Invest. 1994;71(2):279-90.

47. Gomez-Camarillo MA, Almonte-Becerril M, Vasquez Tort M, et al. Chondrocyte proliferation in a new culture system. Cell Prolif. 2009;42(2):207-18.

48. Tamama K, Kawasaki $\mathrm{H}$, Wells A, Epidermal growth factor (EGF) treatment on multipotential stromal cells (MSCs). Possible enhancement of therapeutic potential of MSC. J Biomed Biotechnol, 2010. 2010: p. 795385. 
49. Baer PC, Schubert R, Bereiter-Hahn J, et al. Expression of a functional epidermal growth factor receptor on human adipose-derived mesenchymal stem cells and its signaling mechanism. Eur $\mathrm{J}$ Cell Biol. 2009;88(5):273-83.

50. Tamama K, Fan VH, Griffith LG, et al. Epidermal growth factor as a candidate for ex vivo expansion of bone marrow-derived mesenchymal stem cells. Stem Cells. 2006;24(3):686-95.

51. Rojas-Ortega M, Cruz R, Vega-Lopez MA, et al. Exercise modulates the expression of IL-1beta and IL10 in the articular cartilage of normal and osteoarthritis-induced rats. Pathol Res Pract. 2015;211(6):435-43.

52. Vicari AP, Trinchieri G. Interleukin-10 in viral diseases and cancer: exiting the labyrinth? Immunol Rev. 2004;202:223-36.

53. Trinchieri G. Interleukin-10 production by effector T cells: Th1 cells show self control. J Exp Med. 2007;204(2):239-43.

54. Salcedo R, Worschech A, Cardone M, et al. MyD88-mediated signaling prevents development of adenocarcinomas of the colon: role of interleukin 18. J Exp Med. 2010;207(8):1625-36.

55. Ajeeshkumar KK, Vishnu KV, Navaneethan R, et al., Proteoglycans isolated from the bramble shark cartilage show potential anti-osteoarthritic properties. Inflammopharmacology, 2019.

56. Kapoor M, Martel-Pelletier J, Lajeunesse $D$, et al. Role of proinflammatory cytokines in the pathophysiology of osteoarthritis. Nat Rev Rheumatol. 2011;7(1):33-42.

57. Ng PC, Li K, Wong RP, et al. Proinflammatory and anti-inflammatory cytokine responses in preterm infants with systemic infections. Arch Dis Child Fetal Neonatal Ed. 2003;88(3):F209-13.

\section{Figures}


A

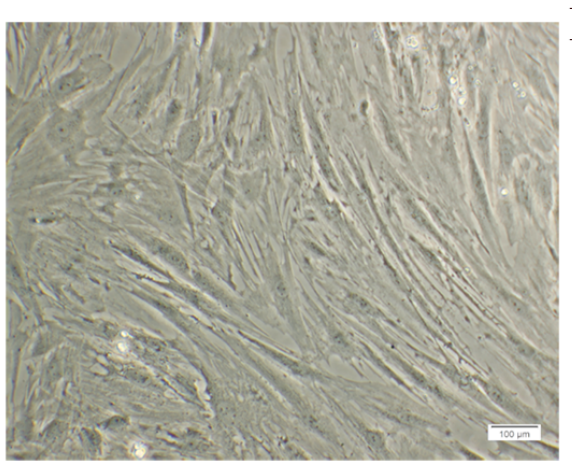

$\mathrm{B}_{1}$

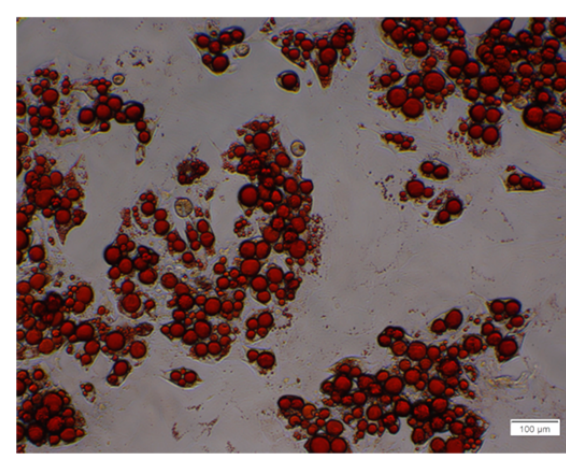

$\mathrm{B}_{2}$

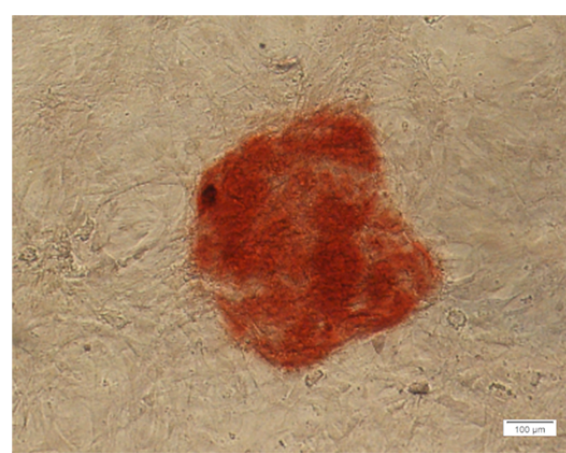

$\mathrm{C}_{1}$

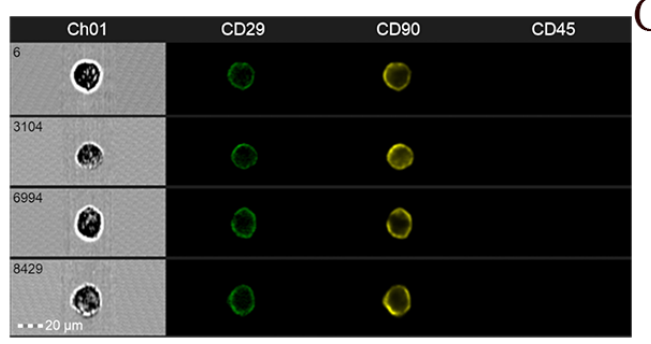

$\mathrm{C}_{2}$

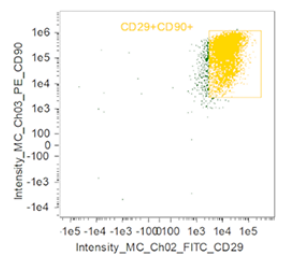

Intensity_MC_Ch02_FITC_CD29, Intensity_MC_Ch03_PE_CD90

\begin{tabular}{|l|c|l|}
\hline Population & Count & $\%$ Gated \\
\hline singelcell \& foucus & 8931 & 100 \\
\hline
\end{tabular} \begin{tabular}{|l|l|l|}
\hline CD29+CD $90+\&$ singelcell \& foucus & 8931 & 100 \\
\hline & 8501 & 95.2 \\
\hline
\end{tabular}

$\mathrm{D}$

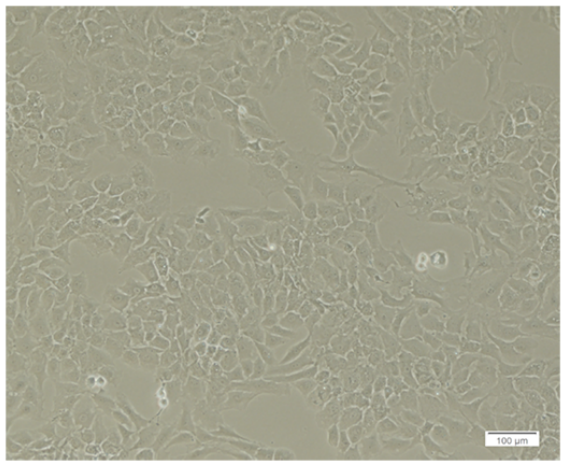

$\mathrm{E}$

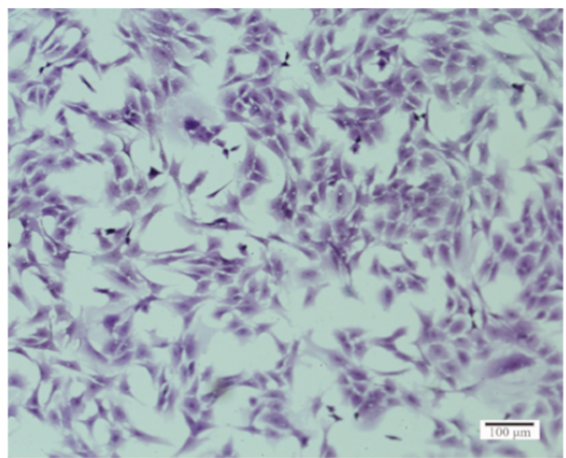

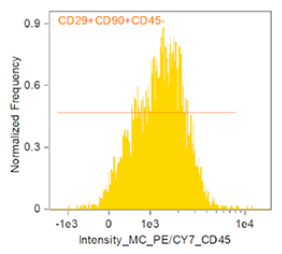

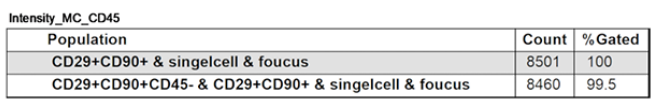

\begin{tabular}{|l|l|l|}
\hline CD29+CD90+CD45- \& CD29+CD90+ \& singelcell \& foucus & 8501 & 100 \\
\hline & 8460 & 99.5
\end{tabular}

\section{Figure 1}

Culture and identification of BMSCs and osteoarthritic chondrocytes. (A) Morphological pictures of BMSCs at passage 3. (B1). Oil red O staining after induced differentiation of BMSCs. (B2).Alizarin red staining after induced differentiation of BMSCs. (C1) Fluorescent photos taken on maker CD29, CD90, CD45 by Amnis ImageStreamX Mark》 Flow Cytometer System. (C2) Flow cytometry analysis of BMSCs. (D) Morphological pictures of primary osteoarthritic chondrocytes. (E) Toluidine blue staining of primary osteoarthritic chondrocytes. 


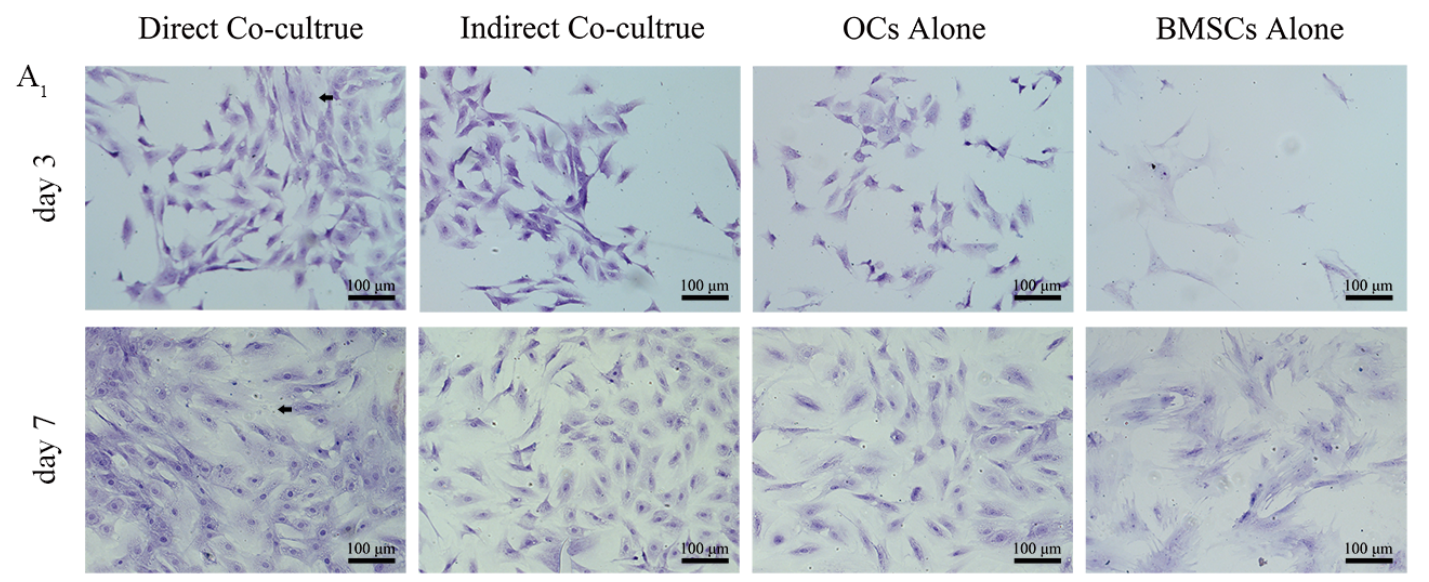

$\mathrm{A}_{2}$
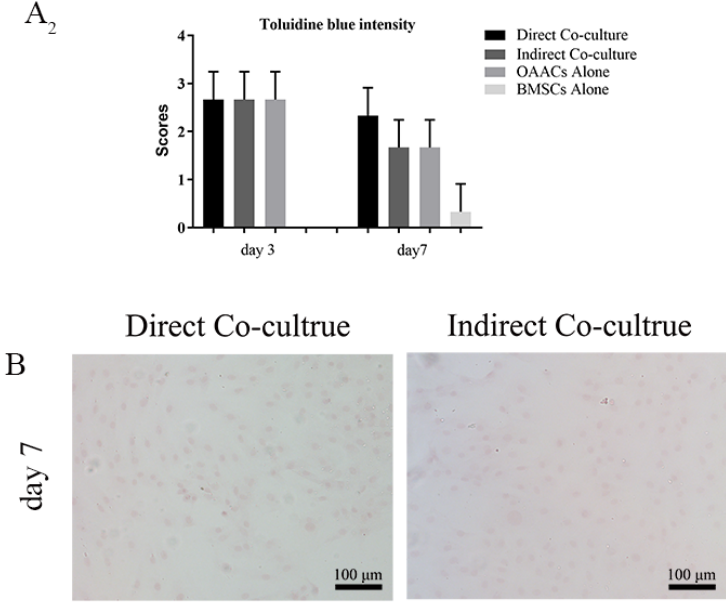

$\mathrm{C}$

r

럼

$\mathrm{D}$

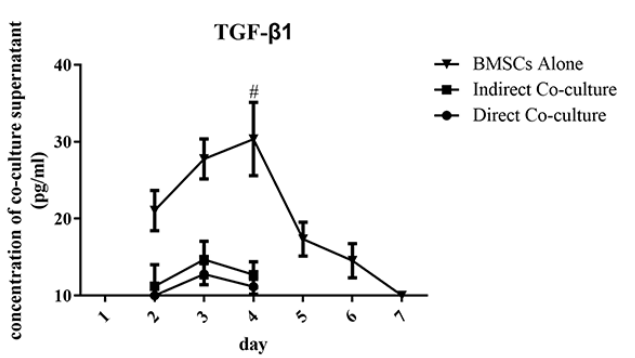

$\mathrm{A}_{3}$

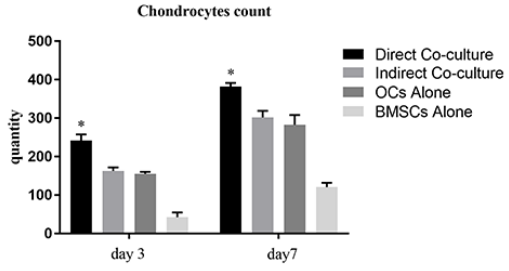

OCs Alone

BMSCs Alone
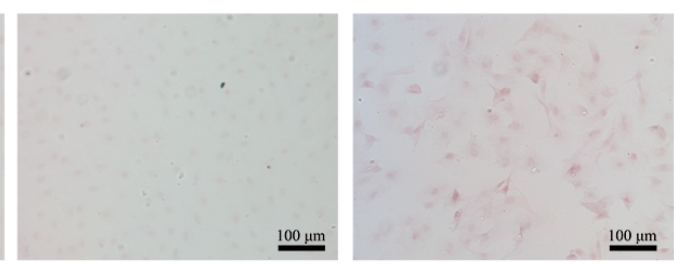

$100 \mu \mathrm{m}$

$100 \mu \mathrm{m}$

$\mathrm{E}$

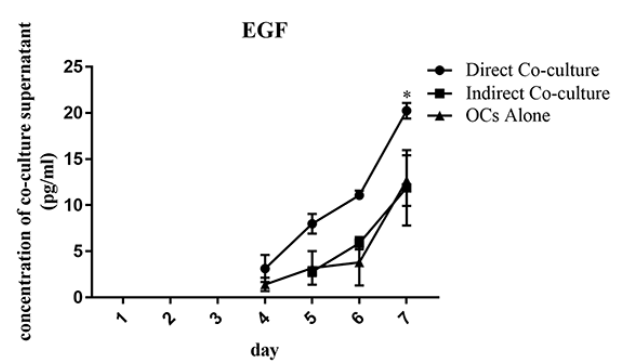

\section{Figure 2}

Staining evaluation and factor concentration detection in co-culture systems. (A1) Toluidine blue staining of cell slides in each group, black arrows indicate BMSCs. $\triangle A 2 \varangle$ Staining intensity of cells in each group

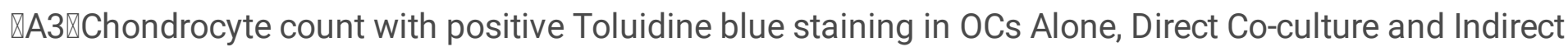
Co-culture (Error bar: mean \pm SEM. ${ }^{*} p<0.05$, versus Direct Co-culture). (B) Alizarin red staining of cell slides in each group on day 7. (C) Trap staining of cell slides in each group on day 7. (D). Concentration 
of TGF- $\beta 1$ (left) and EGF (right) in culture supernatant of co-culture system in each group (Error bar: mean $\pm \mathrm{SEM}$. $\# \mathrm{p}<0.05$, versus BMSCs Alone). $\otimes \mathrm{E})$. Concentration of EGF in culture supernatant of co-culture system in each group (Error bar: mean \pm SEM. ${ }^{*} p<0.05$, versus Direct Co-culture).
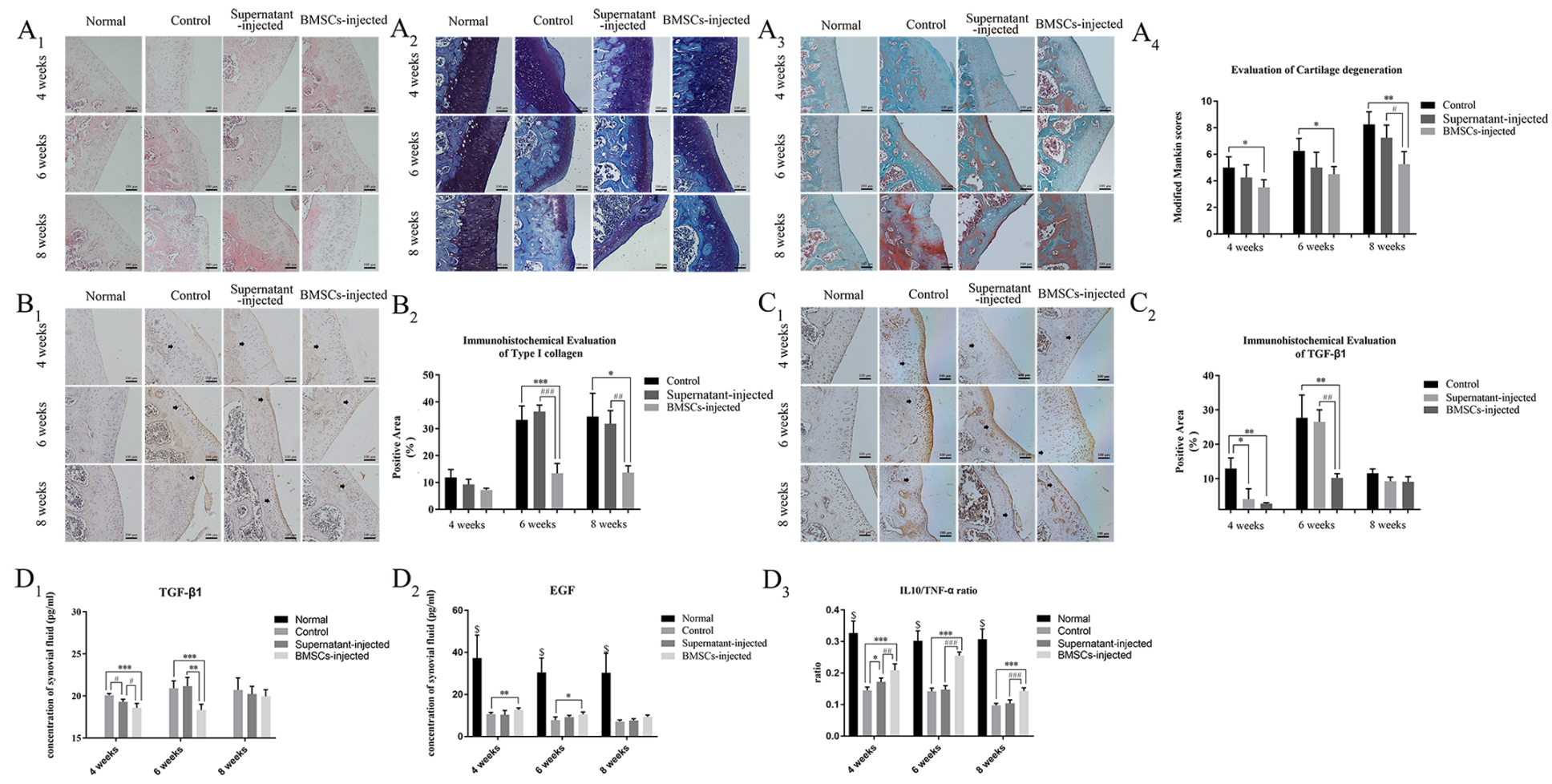

\section{Figure 3}

Representative data of histological analysis of articular cartilage and changes of factors in joint fluid after different ways of treatment. (A1) HE staining of bone sections in different groups. (A2) Toluidine blue staining of bone sections in different groups. (A3) Masson's trichrome staining of bone sections in different groups. (A4) Modified Mankin score was obtained from histology staining in each group (Error bar: mean \pm SEM. ${ }^{*} p<0.05,{ }^{*} p<0.01$ versus Control; $\# p<0.01 ; \# p<0.05$ versus Supernatant-injected). (B1) Expression of Type I collagen protein in paraffin sections of bone sections detected by immunohistochemical staining in each group; (B2) Type I collagen positive area evaluation and Comparison (Error bar: mean \pm SEM. ${ }^{*} p<0.05,{ }^{* \star *} p<0.005$ versus Control; $\# \# p<0.01 ; \# \# \# p<0.005$ versus Supernatant-injected). (C1) Expression of TGF- $\beta 1$ in paraffin sections of knee joints detected by immunohistochemical staining in each group; (C2)TGF- $\beta 1$ positive area evaluation and Comparison (Error bar: mean \pm SEM. ${ }^{*} p<0.05,{ }^{* \star} p<0.01$ versus Control; \#\#p $<0.01$ versus Supernatant-injected). (D1) Concentration of EGF in synovial fluid of different groups (Error bar: mean \pm SEM. ${ }^{* \star *} p<0.005$ versus Control; $\# p<0.05$, \#\#p <0.01versus Supernatant-injected); (D2) Concentration of TGF- $\beta 1$ in synovial fluid of different groups (Error bar: mean \pm SEM. ${ }^{*} p<0.05$, ${ }^{* \star} p<0.005$ versus Control). (D3) The IL-10/TNF-a ratio in different groups (Error bar: mean \pm SEM. ${ }^{\star * \star} \mathrm{p}<0.005$ versus Control; \#p $<0.05$, \#\#p $<0.01$, \#\#\#p <0.005 versus Supernatant-injected). 